\title{
Reconceptualising outdoor adventure education: Activity in search of an appropriate theory.
}

\author{
Mike Brown
}

The University of Waikato

\begin{abstract}
Experiential approaches to learning underpin teaching and learning strategies in outdoor adventure education (OAE). Recent critiques of experiential learning have problematised the individualistic and overly cognitive focus of this approach which creates binaries between experience-reflection and the learner-situation. This paper summarises these critiques and investigates the possibilities made available by understanding OAE from a socio-cultural perspective. Consideration of OAE students as participants in a highly orchestrated community of practice places learning, and observable change, within a socio-cultural frame rather than as primarily a function of cognitive processes within the individual. This position takes seriously the claims made by practitioners of 'seeing evidence of change' and researchers who raise questions about the validity of 'generalised claims' by placing greater emphasis on the situated nature of learning and acting. Moving beyond conceptions of the learner as an autonomous 'processor' of experiences, who is capable of generating context free knowledge, has implications for existing OAE theory and practice.
\end{abstract}

\section{Introduction}

The emphasis on interpersonal and intrapersonal relationships is frequently deemed to be the primary focus of outdoor adventure education (OAE) programmes (Hill, 2007; Priest \& Gass, 1997; Zink \& Boyes, 2006). For example, Ewert and Garvey (2007) have suggested that "one of the most visible and advertised outcomes of adventure education programs is personal growth" (p. 29). As will be discussed in greater detail the emphasis on personal development has lead to the use of teaching and learning strategies in OAE that are largely based on an understanding that learning occurs via the cognitive processing of experiences. The individual is positioned as an autonomous agent who is capable of internalising experiences and applying the new knowledge acquired in one setting to other contexts (Holman, Pavlica, \& Thorpe, 1997; Kemmis, 1985). This view of learning, as individualised knowledge acquisition, overlooks the situated and distributed nature of learning which will be discussed in more detail.

Critical inquiry into understandings of human behaviour coupled with research on experiential learning theory and practice have brought into focus the need to reappraise current OAE pedagogy (Brookes, 2003a, 2003b; Brown, 2003; Fenwick, 2001, 2003a; Hovelynck, 2001; Roberts, 2008; Seaman, 2008; Vince, 1998).

In this paper I will provide a brief overview of experiential learning in $\mathrm{OAE}$, the salient points from critiques of both the experiential learning cycle (Fenwick, 2001, 2003a; Roberts, 2008; Seaman, 2008; Vince, 1998) and the principles of constructivism (Bowers, 2005; Egan, 2002) on which much OAE practice is premised. I will then investigate the possibilities made available through understanding OAE from a socio-cultural perspective. Consideration of OAE students as participants in a highly orchestrated community with its own practices and norms (Lave \& Wenger, 1991) places learning, and observable change, within a socio-cultural frame rather than simply as a function of individual cognitive development. By placing greater emphasis on the social and cultural context that is the learning process, this alternative position takes seriously practitioners' claims of observing changes in students during a course whilst providing an explanation as to why these changes may not be exhibited in other situations.

My aim in this paper is to reframe some understandings of learning and knowing in OAE and to open up alternate ways for OAE programmes to be conducted. Making explicit the underlying principles of the learning theories that are utilised has practical implications for practitioners and participants.

\section{Experiential learning in OAE}

A common approach to implementing experiential learning in $\mathrm{OAE}^{1}$ is the provision of activities coupled with some form of reflection in which learners endeavour to make sense of their experience(s) (Priest \& Gass, 1997; Prouty, 2007). Fenwick (2001) suggests that most experiential educators, regardless of their disciplinary affiliation, "presume the same

1. Whilst recognising that $O A E$ is one manifestation of experiential learning theory it would appear that for some writers in $O A E$ the terms are conflated (e.g., Prouty (2007, p. 4) "The definitions of experiential education and adventure education are merging and becoming less distinguishable..."). 
basic conceptualization of experiential learning: an independent learner, cognitively reflecting on concrete experience to construct new understandings, perhaps with the assistance of an educator, toward some social goal of progress or improvement" (p. 7). The models popularised in OAE literature tend to be derived from Kolb's (1984) model of experiential learning. Vince (1998) has suggested that Kolb's cycle is the pre-eminent model "to express the nature of experiential learning" (p. 304). The four components of Kolb's (1984) model; concrete experience, reflective observation, abstract conceptualization, and active experimentation appear in various forms in a large number of OAE texts, either cited directly or modified (Exeter, 2001; Martin, Cashel, Wagstaff, \& Breunig, 2006; Panicucci, 2007; Priest \& Gass, 1997).

The following illustrate the articulation of the concrete experience-reflection format in OAE texts. Sugarman, Doherty, Garvey and Gass (2000) suggest that, "Participants who reflect on an experience are better able to extract lessons from the experience, to understand themselves in relation to the experience, and to apply the learning to other areas of their lives (de la Harpe \& Radloff, 1997)" (p. 9). The reflective stage of the cycle is often referred to as processing. Luckner and Nadler (1997) suggest that, "Processing enhances the richness of the experience, so it stands out and apart, like the important lines of a page underlined with a yellow highlighter. These unique learnings then can be used again and generalized to other settings" (p. 10).

The metaphors utilised embrace a technicalmechanistic notion of learning, where experience is an 'object' to be internalised and refined to reveal its true meaning. The processing metaphor employed in OAE assumes: that learning happens through cognitive reflection; that experience can be treated as a discrete entity; and that a learner can be separated from his or her concrete experience to process it and generate knowledge (Fenwick, 2001). Loynes (2002) has suggested the use of the production line metaphors (processing, loading, sequencing) inherent in OAE indicate the predominance of a rational, mechanistic, and deterministic approach in which participants may be "oppressed rather than empowered by their managed experience" (p. 116). Loynes (2002) argues that the adoption of a commodified approach to providing OAE experiences, an adrenaline buzz coupled with processing/reviewing intended to elicit "conscious and rational learning outcomes from the experiences" (p. 117), is counter to what should be "the organic and emergent nature of experiential learning as it takes account of environments, individuals, groups, cultures and activities and the experiences that arise from their interaction" (p. 113). Quay (2003) suggests that the stepwise process of reflection on experience, followed by further activity is evidenced in outdoor programs where time is set aside for 'doing' and formal reflection. He considers that this conceptualisation of learning allows it to be placed alongside other mechanistic learning theories. Holman et al. (1997) argue that experiential learning theory replicates the assumptions, principles and methods inherent in cognitivist accounts of learning. Of note are the assumptions that the learner is separate from their social, historical and cultural context and that thinking can be studied as a sequential process of problem solving involving the manipulation of semantic or symbolic codes which represents objects or events (Holman et al., 1997).

Thus, if a person does not appear to learn there is a problem with the individual (mental ability), or the wrong 'input' (activity) or processing technique is being used, hence the advent of unique/novel tasks and the introduction of more sophisticated approaches to facilitation using increasingly 'advanced' techniques (see Gass \& Stevens, 2007; Priest \& Gass, 1997). Holman et al. (1997), writing in the area of management education, have suggested that Kolb's model has been so influential that when managers 'fail to learn' it is commonly assumed to be due to the individual or facilitator rather than there being flaws with the theory itself.

The emphasis on individual autonomy and meaning making reflects what Mehan (1996) has argued is one of the core values of western society; individualism. From a cognitivist perspective an individual's traits and states provide an explanation for human behaviour. A person's success or failure is deemed to be the result of personal effort and hard work. However, an emphasis on the individual as the locus of change "drains discourse of the capacity to deal with the social and cultural dimensions of experience" (Brookes, 2000, p. 2). The propensity to regard the social and cultural dimensions of experiences as external distortions (Brookes, 2000) reinforces the notion that true meaning is found through reflection which removes these 'extraneous' details. The individualising of experience also impoverishes our understanding of the "mutuality and reciprocity in learning" (Seaman, 2008, p. 12) and in doing so overlooks the situated nature of human behaviour. Perhaps, as Seaman (2008) suggests, we should remember that "the idea that experiential learning is by definition a cycle made up of orderly, sequential steps is neither eternal nor universally shared" and "cyclic models might be better valued for their important historical contribution, rather than as active theories of learning" (p. 3).

\section{Recent critiques: Opening the door to a reconceptualised OAE theory of learning}

Several recent publications, from both within and beyond OAE literature, provide an opportunity to reflect on the pre-eminent position afforded to 
experiential learning in OAE. Collectively these critiques or alternate positions present a reasoned basis for reconceptualising OAE learning theory.

\section{A critique of dispositionist assumptions in OAE: An emphasis on the situation}

Brookes' (2003a, 2003b) review of psychological literature called into question claims that personal transformations resulting from participation in OAE programmes were permanent, that is, were changes in a person's disposition. In contrast, Brookes (2003a) argued that research supported the influential role of the situation in eliciting particular behaviours. He did not deny that behavioural changes might be observed, the central issue was the 'transferability' of any such changes to different settings. As he noted, "individuals can become a 'different person' in certain situations, but those differences are not predictive of behaviour in other situations" (Brookes, 2003a, p. 56). Thus observing a student display 'different' behaviours on camp may not adequately be explained by claims that these changes are likely to be durable across contexts . For as Brookes (2003a) suggests, OAE practices may encourage "conformist effects" (p. 59) whilst Seaman (2007) contends that the dependability of OAE outcomes may be a function of the structured and highly mediated physical and social conditions of many experiences.

In arguing against a dispositional view of fixed traits that are consistent across situations, Brookes (2003a, 2003b) raises an alternate perspective that takes into account the social, historical, and geographical factors influencing human behaviour. Brookes' critique drew heavily on the language of psychology, both social and personality strands, and in particular the works of Ross and Nisbett (1991) and Shoda and Mischel (2000). This paper extends the general tenant of Brookes' argument, in regards to the situated nature of human activity, by drawing on socio-cultural theory rather than personality and social psychology.

\section{Critiques of experiential learning theory}

Such is the 'bedrock' status of experiential approaches that critiques of accepted experiential practices are relatively rare within OAE literature (for existing critiques see Bell, 1993; Brown, 2003; Fox, 2008; Hovelynck, 2001; Loynes, 2002; Quay, 2003; Ringer, 1999; Roberts, 2008; Seaman, 2008; Wurdinger, 1995).

However, within the adult education and management literature there have been a number of challenges to the established orthodoxy of experiential learning (Fenwick, 2001, 2003a; Holman et al., 1997; Michelson, 1996, 1999; Vince, 1998). In a comprehensive critique Fenwick (2001) addressed issues of power and knowledge production, identity, positioning of the learner and educator, internal epistemological contradictions, and the coercive and regulatory practices of experiential learning.

In addition, critiques by social commentators and philosophers of education have been levelled at the very foundations of constructivist approaches to learning which inform experiential learning theory and practice (Bowers, 2005; Egan, 2002). Bowers' critique of constructivist learning theories is based on; its assumptions based on social Darwinism (also a focus of Egan's work); its anthropocentric focus which fails to address the deepening ecological crises; the role that it plays in undermining the diverse cultural commons; its contribution to the rise of individualism; and for acting as a Trojan Horse for western imperialism.

Bowers (2005) and Egan (2002) argue that the major proponents of constructivist theory, in its different guises, (e.g., Dewey, Piaget and Freire) assume that change, in the form of progressive development, is the dominant feature of everyday life. An educator's role is therefore to prepare learners to cope with this constant change by promoting skills such as critical reflection, experimental inquiry, and autonomous thinking to encourage individual meaning making. Implicit in constructivism's adherence to an "evolutionary interpretive framework" (Bowers, 2005, p. 19) is the belief that 'advanced' cultures employ experimental inquiry and critical reflection in contrast to 'primitive' cultures that rely on traditions. The assumption that change is inherently progressive positions those who seek to maintain traditions and practices inherited from earlier generations as reactionary or 'out of touch.' Bowers contends that constructivist agendas can become a powerful form of colonisation, in that the acceptance of individual meaning making as a universalised approach to learning, becomes the accepted pedagogical approach which should be adopted (or imposed through educational reform).

For Bowers (2005) the problem that arises with the spread of constructivist educational practices is the failure of its advocates,

to qualify their theories by acknowledging that experimental inquiry and critical reflection are highly useful in certain situations, but that other approaches to knowledge and its intergenerational renewal might be more appropriate in other contexts - and the contexts might vary between different cultures. (p. XI)

He argues that the advocacy and primacy of individual meaning making works to undermine intergenerational traditions and community life that have formed the basis of different cultures and which have provided ecologically sustainable practices. 
Bowers (2005) argues that constructivist pedagogies, based on the assumption that students learn more effectively when they construct their own knowledge, potentially restricts students' knowledge to what they can learn from their own direct experience.

He suggests that democracy needs a more complex set of understandings than currently made available in universalised constructivist approaches. For example, it is clear that knowledge of ecologically sustainable practices is transmitted between generations through a variety of cultural patterns rather than being discovered afresh by each successive generation. Bowers emphasises the necessity of acknowledging multiple ways to learn and know; critical reflection, experimental inquiry, dialogue, student experiences and interest, hands-on problem solving, direct transmission, and embodied ways of knowing are all valid and can enrich our conceptions of learning.

Attention will now turn to two specific problematic binaries in experiential learning.

\section{Problematic binaries in experiential learning}

Experiential learning is often claimed to be holistic (Proudman, 1995; Prouty, 2007), therefore it is somewhat ironic that it is the binaries of: (a) abstraction of meaning from the experience; and (b) the learner from the situation, which form the basis of challenges to this conceptualisation of learning. These binaries reflect the view of learning and knowing as readily transportable commodities; an understanding that is highly problematic.

\section{Internalisation and rational reflection: Abstracting meaning from experience}

Inherent in the OAE position is a belief in the ability of the learner to construct personal meaning from experience through a largely rational and conscious process (e.g. various cyclic models, Joplin, 1995; Kolb, 1984). However the focus on reflection in experiential learning has been criticised for being too simplistic, reductionist and linear (Bell, 1993; Fenwick, 2003a; Fox, 2008; Holman et al., 1997; Roberts, 2008; Sawada, 1991). Critiques of the experience - reflection binary are focussed on several overlapping issues.

Firstly, rational reflection and abstract meaning making requires an understanding of a 'self' that is capable of detached and reasoned reflection. The conceptualisation of self, as a rational and unified entity, has been called into question by a number of writers from various perspectives (Fenwick, 2001; Michelson, 1996). Reflection emphasises rationality, control and mastery "which feminist theories of workplace learning have criticized as a eurocentric, masculinist view of knowledge" (Fenwick, 2001, p. 19). Bowers' (2005) and Egan's (2002) critique of the influence of social Darwinism is reiterated in Michelson's (1996) connection between the reflective process and the larger discourse of progress. She argues that through reflection "we partake of the dream of reason, the Western tale of progress through rationality" (Michelson, 1996, p. 439). She also suggests that the distinction between experience and "reflection as a highly cognitive processing stage in which the learning actually takes place... valorizes emotional detachment, physical distance and rationality, thereby imposing an epistemological hierarchy that is deeply complicitous with power differentials of gender, class and race" (p. 438). Poststructuralists, for example would argue that the self is an illusory image. The intention here is not to enter into a debate on the self, rather it is to indicate that unitary and stable representations of the self are contestable. This questions one of the fundamental assumptions underpinning OAE theories of learning; that through reflection an individual can abstract (or extract) the 'real' meaning from experience.

It has also been suggested that learning by reflection does not provide an adequate explanation of the role of desire in experience and learning. Proponents of psychoanalytic theories and the role of the unconscious in experience and learning (e.g., Britzman, 1998; Vince, 1998) maintain that desire is a "foundational principle of human experience and knowledge" (Fenwick, 2001, p. 19). Vince (1998) suggests there is an assumption by the advocates of the experiential cycle "that people are open to experience, not defended against it. People's behavior... emerges out of deeply held patterns and unconscious processes that both encourage and discourage learning from experience" (p. 308). The notion that we are able to derive abstracted/ rational concepts through cognitive reflection on experience, "sidesteps what Britzman (1998a) calls the ambivalences and internal 'vicissitudes' bubbling in the unconscious" (Fenwick, 2001, p. 19). According to Britzman (1998) the unconscious influences how we interpret experiences, and therefore our meaning making, in unpredictable ways. This unpredictability in meaning making is compounded by the inherently political and ideological nature of reflection (Kemmis, 1985). Reflection, according to Kemmis, is political in that it occurs in contexts where the self-interests of different people will be served differentially. Whilst the ideological component is revealed in the distinction between the messiness of experience and order supposedly imposed by rational reflection which is intended to find meaning or greater clarity which was missing in 'mere' experience (Kemmis, 1985). 
The second major criticism of the experience - reflection binary is that it is another version of the Cartesian mind (cognitive reflection) - body (experience) split (Michelson, 1999).

The body has been somehow banished from learning, along with the body's enmeshments in its social, material and cultural nets of action. Then, appropriated by both school and workplace, the learning that is harvested from bodies in action has been forced into normalizing categories, commodified, and credentialed. (Fenwick, 2003a, p. 10)

Kemmis (1985) suggests that because reflection is something deemed to occur inside the head we tend to think of it as an internal psychological process. However, he warns that to view reflection in this light ignores the situational and embodied experiences that give reflection its very character and significance.

The proposition that an individual can somehow 'distance' him or her self from experiences and reflect or process them over simplifies the embodied, situated and discursive constituents of experience. As Kemmis (1985) remarked, "We do not pause to reflect in a vacuum" (p. 141). All experiences are mediated through our bodies and our cultural lens; there is no such thing as a pure, immediate or transparent experience (Fox, 2008). Seaman (2007) argues that the recognition that learning is mediated through cultural understandings challenges "assumptions about the radical autonomy of learners, about 'direct experience,' and about the centrality of independent, cognitive reflection in experiential learning" (p. 3).

Thirdly, what or who determines what constitutes 'concrete experience' and the boundaries between experience and reflection? Holman et al. (1997) suggest that "there may be no reason other than symbolically to differentiate between reflection and the process of experiencing. Both can be considered as part of the same argumentative process which constructs meaning" (p. 142). Experience is not a stable entity, rather it is multi-layered and confounds attempts to bound and rationalise it into categories that can easily be managed (Bell, 1993; Fox, 2008; Michelson, 1999).

Some OAE programmers have perhaps drawn a somewhat arbitrary line between being active and then structuring reflection on these experiences to aid meaning-making to enhance learning. As Fenwick (2000) asks:

What manner of learning can be conceived that is not experiential, whether the context be clearly educational or not? Experience embraces reflective as well as kinesthetic activity, conscious and unconscious dynamics, and all manner of interactions among subjects, texts, and contexts. (p. 244)

\section{The separation of the learner and learning from the} situation

The second problematic binary is the tendency to separate the learner from the context in which a skill, behaviour or attribute was practiced or observed. This decontextualisation is evident in the importance placed on facilitating generalisable concepts or principles that can (supposedly) be transferred across different contexts (e.g., OAE setting, home, work, school). The belief in decontextualised knowing and acting is based on the assumption that an autonomous learner is largely independent of social and spatial relationships (Holman et al., 1997). The specifics of the context are deemed to be of little or no relevance and can be 'stripped away' to reveal a 'context-free' universal principle. Fenwick (2001) suggests that in Kolb's model little consideration is given to context as part of the learning process. Where context is discussed in experiential learning (e.g., Boud, Keogh, \& Walker, 1985) it tends to be viewed as a space separate from the learner; context is 'something' that influences the learner but is inherently distinct from the learner who maintains a detached autonomy (Fenwick, 2001). However, as Jarvis (1987) reminds us, "learning is not just a psychological process that happens in splendid isolation from the world in which the learner lives, but is ultimately related to the world and affected by it" (p. 11). Brown, Collins and Duguid (1989) suggest that the separation between doing and knowing overlooks the purpose of the activity and the specifics of the situation. In this view the context is viewed as "merely ancillary to learning... but fundamentally distinct and even neutral with respect to what is learned" (p. 32). However, research into learning provides evidence that this separation of what is learned from how it is learned and used is no longer tenable (Hutchins, 1993; Lave, 1988).

The activity in which knowledge is developed and deployed, it is now argued, is not separable from or ancillary to learning and cognition. Nor is it neutral. Rather, it is an integral part of what is learned. Situations might be said to co-produce knowledge through activity. Learning and cognition, it is now possible to argue, are fundamentally situated. (Brown et al., 1989, p. 32)

Additionally, the question of what constitutes one context as distinct from another is problematic. Thus contexts, experiences, and reflection(s) do not 
lend themselves to being neatly contained within clearly definable boundaries as simplified models and practice would suggest.

Learning cannot be separated from, and treated independently of, the social, political, historical and cultural context in which it occurs. By way of example, Seaman (2007), drawing on Cultural-Historical Activity Theory (CHAT), illustrates how a learner's experience in OAE is mediated through cultural and institutional tools. He demonstrates that experience(s) and meaning making are not individual events but rather collaborative processes. What is learned is situated in a specific place, directed to a purpose or goal, with a particular group of people who bring differing knowledge and attributes. Learning is contextualised according to the demands of the task and the resources available in the situation in which people find themselves. What is emphasised, what is discussed or omitted, the tools that are utilised (physical, cognitive, linguistic etc.) and the knowledge that is valued are functions of the culture and social power relationships which are deeply saturated with meaning (Vince, 1998).

At a conceptual level there are several problems with the model of experiential learning used in OAE. From a practitioner's perspective there are also a number of questions that remain unanswered and problematic. For example, how does an outdoor educator account for variability in the behaviour of participants during a programme? Why do students appear to act 'out of character' in one context given they have recently been performing so well? Why is it that post programme some students are able to enact change whilst others slip back into old routines? Proponents of the existing approach to learning might maintain that the apparent lack of success is of a cognitive (lack of ability), or technical nature (inappropriate facilitation). Efforts to improve existing practices, as evidenced in the advent of multiple generations of facilitation and devising unique and highly structured activities to ensure students 'get it,' do not address the inherent difficulties and problematic assumptions which underpin the way learning and the learner is understood in OAE. A preoccupation and concentration on the individual as an agent for change are in marked contrast to socio-cultural approaches to learning which regard the situation as integral to the learning process. From this perspective the situation is not a variable that effects learning, rather it is indivisible from learning. Greater awareness of the situated nature of knowing/acting may offer more positive avenues for learners in OAE than recourse to theories of learning which place undue emphasis on the learner as a 'bearer' of context-free knowledge. It is to a brief explanation of situated ways of knowing and acting that attention will now turn.

\section{Situated perspectives on learning}

A situated perspective ${ }^{2}$ insists that learning and knowing can best be understood in, and cannot be separated from, the social and cultural-historical context in which it occurs (Lave, 1988, 1996; Rogoff, 2003). This paper expands on this definition by adding the physical environment as an explicit component of the context rather than one that is assumed, yet remains silenced. To be 'situated' is to be located in a place which is ascribed with social and culturalhistorical meanings which combined with the physical features afford and constrain activity.

Situated perspectives pay attention to the learner's changing participation in communities of practice as the focal point of the learning process rather than viewing learning solely as the outcome of individual cognitive reflection. "The distinguishing characteristic of the situative perspective is its theoretical focus on interactive systems that are larger than the behavior and cognitive processes of an individual agent" (Greeno, 1998, p. 6). A situated perspective does not deny that cognitive processing occurs, however it draws upon a body of empirical research (Hutchins, 1993; Lave, 1988) to emphasise:

the relational interdependency of agent
and world, activity, meaning, cognition,
learning, and knowing. It emphasizes the
inherently socially negotiated character
of meaning and the interested, concerned
character of the thought and action of
persons-in-activity. This view also claims
that learning, thinking, and knowing are
relations among people in activity in, and
arising from the socially and culturally
structured world. (Lave \& Wenger, 1991,
pp. 50-1)

Thus learning is inextricably linked to the nature of the activity and is situated in place(s) "tethered to a particular terrain of resources and relationships" (Carr et al., 2008, p. 9). From a situated perspective the context, the activity, the participants and the tools (physical and cultural) do not merely influence learning and what counts as knowledge - they constitute learning and knowing.

2. I have used the term 'situated perspective' to refer to the broad literature incorporating socio-cultural, sociohistorical, culturalhistorical, and activity theory perspectives. This position draws upon the work of Engestrom, Greeno, Lave, Rogoff, Vygotsky, and Wenger. As noted, I wish to make explicit the need to recognise the silenced "place" aspect of situated activity. 


\section{Communities of practice}

The social relationships that are formed in the pursuit of shared activities create practices that are common to that community. These communal ways of acting give rise to communities of practice (Wenger, 1998). The concept of a community of practice does not necessarily denote, "a well-defined identifiable group, or socially visible boundaries. It does imply participation in an activity system about which participants share understandings concerning what they are doing and what that means in their lives and for their communities" (Lave \& Wenger, 1991, p. 98). The premise that the situation in which knowledge is developed and used is integral to what is learned means that communities of practice may develop different understandings in apparently similar circumstances. By way of example, Brown et al., (1989) suggest that the manner in which a carpenter uses a chisel is different to a cabinet maker. The two communities of practice determine how a tool, in this case a chisel, is used. How the worker learns to use the chisel and what s/he knows about its uses are shaped by the practices of the community rather than an inherent property or explicit invariant rule determining 'chisel use.' In the example above the tool is a physical object but tools are also ways of acting, the procedures and the cultural norms and the worldview which participants have available to them. As with physical tools:

Conceptual tools similarly reflect the cumulative wisdom of the culture in which they are used and the insights and experience of the individuals. Their meaning is not invariant but a product of negotiation within the community. Again, appropriate use is not simply a function of the abstract concept alone. It is a function of the culture and the activities in which the concept has been developed. (Brown et al., 1989, p. 33)

The activities of a group, and the meanings and purposes ascribed to them, are the result of negotiations between participants in culturally and historically mediated practices. What is learned is firmly situated in the socio-cultural and physical milieu. Knowledge is therefore indexical, it indexes the situation in which it arises and the situation connects the activity to the representations that are developed (Brown et al., 1989). The implication that learning, knowing and ways of acting are situated in communities of practice means it is possible to move beyond conceptions of knowledge as an abstract, self-contained and readily transportable entity. What is counted as knowledge and how it is used depends on the nature of the community of practice.
From a situated perspective effort is directed at understanding the kinds of social engagements that might provide efficacious conditions for learning to take place (Hanks, 1991).

This shift has interesting consequences.... On the one hand, it implies a highly interactive and productive role for the skills that are acquired through the learning process. The individual learner is not gaining a discrete body of abstract knowledge which (s)he will then transport and reapply in later contexts. Instead, (s)he acquires the skill to perform by actually engaging in the process, under the attenuated conditions of legitimate peripheral participation. (Hanks, 1991, p. 14)

\section{Legitimate peripheral participation}

Legitimate peripheral participation (Lave \& Wenger, 1991) refers to the relations between new participants in a community of practice and those who are 'old-timers.' It is concerned with the processes (activities, identities and artefacts) by which new participants become part of a community of practice. As newcomers gain mastery of skills and knowledge they are able to move toward full participation in the practices of a community. Whilst acknowledging that the term is somewhat unwieldy it is used to indicate the changing nature of "participation and identity transformation in a community of practice" (Wenger, 1998, p. 11). Lave and Wenger caution against defining the term through the use of the contrary terms (e.g., illegitimate, central). Wenger (1998) states that "Peripherality provides an approximation of full participation that gives exposure to actual practice" (p. 100). It can be achieved in various ways, including lessened intensity, special assistance, lessened consequences as the result of errors, and close supervision. The concepts of a community of practice and legitimate peripheral participation reframes the notion of learning from individualistic notions of acquisition and internalisation to co-participation in the curriculum of the community (Lave \& Wenger, 1991). Learning and knowledge are not independent substances to be consumed, rather they emerge, develop and are adapted in the process of participation in the activity (Fenwick, 2001). What is counted as knowledge depends on the particular task, the skills and relationships that are found and evolve in the new situation. Acting appropriately is not simply a matter of applying ' $x$ ' solution from ' $y$ ' situation, rather it is a matter of negotiating the highly nuanced and interactive systems that are valued in this community 
of practice. Implicit in this process is the recognition of affordances and constraints that may occur across situations.

\section{Implications for OAE learning theory}

An appreciation of the socio-cultural and situated nature of learning differs from traditional cognitive theory which divides the learner from the world of experience (Lave, 1996) and views knowledge as mental representations that are stored in the head (Gee, 2008). The 'placement' of learning in relationships extends the current psychological focus in OAE learning theory (Quay, 2002) and challenges existing practices. OAE's frequent treatment of the outdoor context as a backdrop or medium for personal growth (Ewert \& Garvey, 2007) has favoured both individual autonomy and detachment of the individual from the specifics of the situation. For example, Lave's (1996, p. 23) 'detached view of context' is exemplified in Walsh and Golins (1976) model of learning in OAE. This early and influential model lays the foundation for the orchestration of difference inherit in many OAE programmes. The constituent elements of a prescribed physical environment, which is unfamiliar to the learner and which contrasts with everyday life, coupled with "a unique social environment" and "characteristic problem-solving tasks" (Walsh \& Golins, 1976, p. 6) combine to make this a community of practice with a focus on specific activities, group culture and practices. Given the orchestrated otherness, OAE is then required to justify its educational value by recourse to a series of abstract and generalisable principles that are not dependent on the novel situations in which they were 'acquired.' This approach is based on conceptions of learning and the learner that are no longer tenable.

A socio-cultural and situated approach goes some way to locating the field within contemporary discourses of both adult education (Fenwick, 2003b, 2007) and more general educational reform movements in recognizing the role of culture in educational practice (Bishop \& Berryman, 2006; Bishop \& Glynn, 1999; Lave, 1996; Lave \& Wenger, 1991; Rogoff, 2003; Wenger, 1998). A recognition of the 'holistic' nature of learning (people, place, activity, culture) is more sympathetic to the struggles and tensions of everyday practices and relieves the individual of notions of failure when practices that were successful in the outdoor setting fail to materialise in 'real life.' By acknowledging the situated nature of learning and knowing in OAE we may be more able to assist participants to recognise elements in OAE practice that enable or hinder success in this situation, with these people, at this time. Openness to the interactive and changing nature of situations has the potential to facilitate learning as difference in perceptions, or challenges to pre-existing ways of acting, may encourage experimentation and discovery. Making overt the particularities of the current community of practice and the various participatory positions adopted orients learners to the nuanced and negotiated nature of learning in specific situations. For example, a possible outcome from an abseiling session might be raised awareness of the role of feedback in the learning process (through observation and direct experience) which leads to changing participation in this activity rather than as an activity that built 'trust' (which can be applied irrespective of the context). Attention to the situationally specific relationships/conditions that enabled or constrained participation opens up opportunities for dialogue without recourse to notions of transfer of abstract concepts. This is a subtle but important shift in focus and emphasis. Recognising that outdoor experiences, like all lived-experiences, are conducted within particular communities of practice, places OAE programmes within in a vast web of communities of practice. On the one hand OAE experiences are no longer 'unique' sites of learning they are another community of practice with particular goals and outcomes. On the other hand however, they are 'unique' or 'special' in the same way that all communities of practice are. An acknowledgement of this is both restricting and liberating. It is restrictive in that we should be more guarded about the claims made regarding generalised learning, however it is liberating in that we are freed from the need to make grandiose claims that are difficult to substantiate. Perhaps it is timely to reflect on claiming more modest outcomes that relate to outdoor education practice (e.g., the ability to cook for a group, to navigate, and to consider the well-being of others when planning a journey). Outdoor educators are undoubtedly effective at establishing communities of practice and utilising tasks that shape particular behaviours which are generally deemed to be desirable (Brookes, 2003a, 2003b; Seaman, 2007). However, we must be mindful not to confuse conformity with learning, nor to reify the communities of practice within OAE programmes as more authentic than other communities of practice.

\section{Concluding thoughts}

The socio-cultural and situated perspectives discussed here calls for a rethinking of the nature of direct experience and reflection. It seeks to resolve the problematic mind/body and person/situation dichotomies evidenced in contemporary OAE. The more modest approach advocated sites the learner as a co-participant in a community of learners, not as an independent and autonomous actor who has either succeeded or failed to learn. This conceptualisation has important implications in regards to the claims made in regards to the 'transferable' benefits of participation in outdoor activities and the practices associated with facilitation for transfer. This issue is explored further in a forthcoming paper. Understanding the socio-cultural elements that constitute the learning environment may be more supportive of student learning than efforts 
to imagine future scenarios in which an abstracted principle will apply. The strength of experiential learning lies in its placement of learning in activity. A situated perspective re-emphasises learning in experience (Wilson, 1993) yet provides a caution about practices which attempt to reify abstraction and the generalisability of concepts disconnected from the activity, place and socio-historical practices of the community of learners. A situated perspective provides an explanation for observable changes in students during an outdoor programme as they move from 'new-comers' to positions of enhanced participation through their changing involvement in the activities of this community of practice.

Moving beyond the constructivist assumptions has important implications for existing OAE theory and opens up avenues for exploring different approaches to practice. A situated approach to learning questions the applicability of highly novel tasks, the risks that are often inherent in such activities, and the associated 'technologies of transfer' which currently dominate many aspects of OAE provision. In contrast to 'big bang' or 'high impact' programmes a situated approach may encourage programme designers and participants of outdoor programmes to develop on-going relationships with others who share similar interests and activities and specific outdoor environments (Brookes, 2003b). Who we are, or who we might become is inseparable from who we are with, where we are, and what we are doing (Brookes, 2003b; Brown, 2008).

From a socio-cultural perspective learners are freed from the performative requirement to 'exhibit' learning or new insights that might (or might not!) be applicable at home, school or the workplace at some unspecified time in the future. It does not deny that students may change their behaviour as the result of participation in a programme, however it does not place an unrealistic onus on the student as the principal agent of change.

This paper takes seriously the challenges to experiential learning theory and has sought to provide an explanation of learning in $\mathrm{OAE}$ that honours the learner and outdoor educator whilst not placing unreasonable expectations on the learner regarding future action. In this sense this work attempts to further our understanding of experiential learning in a moral and sensitive manner. Continuing reference to direct experience followed by reflection, is as Seaman (2007) reminds us, "an extremely limited way to understand the physical, social and individual process of learning in adventure education" (p. 16). By heeding Fenwick's (2001) call to continually challenge the phenomenon of experiential learning the position advocated here seeks to expand and advance understandings of learning in OAE which are firmly based in the social and cultural world of participants (Quay, 2003).

\section{Acknowledgements}

My thanks to Professor Margaret Carr for comments on an earlier draft of this paper. I acknowledge the feedback provided by the reviewers whose comments tightened the paper. This paper is based on a presentation made at the 4th International Outdoor Education Research Conference, Victoria, 2009.

\section{References}

Bell, M. (1993). What constitutes experience? Rethinking theoretical assumptions. Journal of Experiential Education, 16(1), 19-24.

Bishop, R., \& Berryman, M. (2006). Culture speaks: Cultural relationships and classroom learning. Wellington, NZ: Huia.

Bishop, R., \& Glynn, T. (1999). Culture counts: Changing power relations in education. Palmerston North, New Zealand: Dunmore Press.

Boud, D., Keogh, R., \& Walker, D. (1985). Promoting reflection in learning: A model. In D. Boud, R. Keogh \& D. Walker (Eds.), Reflection: Turning experience into learning (pp. 18-40). London: Kogan Page.

Bowers, C. (2005). The false promises of constructivist theories of learning: A global and ecological critique. New York: Peter Lang.

Britzman, D. (1998). Lost subjects, contested objects: Toward a psychoanalytic inquiry of learning. Albany, NY: SUNY Press.

Brookes, A. (2000, January 14-17). Dwelling in the details: The fallacy of universal nature experience, and the myth of the essential self. Paper presented at the DEEP seminar on Outdoor Education and Deep Ecology in the 21st century, Haeverstolen, Rennebu, Norway.

Brookes, A. (2003a). A critique of Neo-Hahnian outdoor education theory. Part one: Challenges to the concept of "character building." Journal of Adventure Education and Outdoor Learning, 3(1), 49-62.

Brookes, A. (2003b). A critique of Neo-Hahnian outdoor education theory. Part two: "The fundamental attribution error" in contemporary outdoor education discourse. Journal of Adventure Education and Outdoor Learning, 3(2), 119-132.

Brown, J., Collins, A., \& Duguid, P. (1989). Situated cognition and the culture of learning. Educational Researcher, 18(1), 32-42. 
Brown, M. (2003). Paraphrases and summaries: A means of clarification or a vehicle for articulating a preferred version of student accounts? Australian Journal of Outdoor Education, 7(2), 25-35.

Brown, M. (2008). Outdoor education: Opportunities provided by a place-based approach. New Zealand Journal of Outdoor Education, 2(3), 7-25.

Carr, M., Peters, S., Davis, K., Bartlett, C., Bashford, N., Berry, P., et al. (2008). Key learning competencies across place and time: Kimihia te ara totika, hei oranga mo to ao. Wellington, New Zealand: New Zealand Council for Educational Research.

Egan, K. (2002). Getting it wrong from the beginning: Our progressivist inheritance from Herbert Spencer, John Dewey, and Jean Piaget. London: Yale University Press.

Ewert, A. W., \& Garvey, D. E. (2007). Philosophy and theory of adventure education. In D. Prouty, J. Panicucci \& R. Collinson (Eds.), Adventure education: Theory and applications (pp. 19-32). Champaign, IL: Human Kinetics.

Exeter, D. (2001). Learning in the outdoors. London: The Outward Bound Trust.

Fenwick, T. (2000). Expanding conceptions of experiential learning: A review of the five contemporary perspectives on cognition. Adult Education Quarterly, 50(4), 243-272.

Fenwick, T. (2001). Experiential learning: A theoretical critique from five perspectives. Columbus, OH: ERIC Clearinghouse on Adult, Career, and Vocational Education.

Fenwick, T. (2003a, 27-29 June). Inside out of experiential learning: Troubling assumptions and expanding questions. Paper presented at the Researching Learning Outside the Academy, Glasgow Caledonian University.

Fenwick, T. (2003b). Rethinking processes of adult learning. Retrieved 23 September, 2003 from www.ualberta. $\mathrm{ca} / \sim$ tfenwick/ ext/pubs / print/ adultlearning.htm

Fenwick, T. (2007). Towards enriched conceptions of work learning; Participation, expansion and translation/ mobilization with/in activity. Human Resource Development Review, 5(3), 285-302.

Fox, K. (2008). Rethinking experience: What do we mean by this word "experience"? Journal of Experiential Education, 31(1), 36-54.

Gass, M. A., \& Stevens, C. (2007). Facilitating the adventure process. In D. Prouty, J. Panicucci \& R. Collinson (Eds.), Adventure education: Theory and applications (pp. 101-123). Champaign, IL: Human Kinetics.
Gee, J. P. (2008). A sociocultural perspective on opportunity to learn. In P. Moss, D. Pullin, J. P. Gee, E. Haertel \& L. Young (Eds.), Assessment, equity, and opportunity to learn (pp. 76-108). Cambridge, NY: Cambridge University Press.

Greeno, J. (1998). The situativity of knowing, learning and research. American Psychologist, 53(1), 5-26.

Hanks, W. (1991). Foreword. In J. Lave \& E. Wenger (Eds.), Situated learning: Legitimate peripheral participation (pp. 1324). Cambridge, NY: Cambridge University Press.

Hill, A. (2007). An examination of New Zealand secondary school teachers' beliefs about outdoor education from a critical perspective. Unpublished PHSE 40 Research Report. University of Otago.

Holman, D., Pavlica, K., \& Thorpe, R. (1997). Rethinking Kolb's theory of experiential learning in management education. Management Learning, 28(2), 135-148.

Hovelynck, J. (2001). Beyond didactics: A reconnaissance of experiential learning. Australian Journal of Outdoor Education, 6(1), 4-12.

Hutchins, E. (1993). Learning to navigate. In S. Chaiklin \& J. Lave (Eds.), Understanding practice: Perspectives on activity and context (pp. 35-63). Cambridge: Cambridge University Press.

Jarvis, P. (1987). Adult learning in the social context. London: Croom-Helm.

Joplin, L. (1995). On defining experiential education. In K. Warren, M. Sakofs \& J. Hunt, Jr. (Eds.), The theory of experiential education (3rd ed., pp. 15-22). Dubuque, IA: Kendall / Hunt.

Kemmis, S. (1985). Action research and the politics of reflection. In D. Boud, R. Keogh \& D. Walker (Eds.), Reflection: Turning experience into learning (pp. 139-164). London: RoutledgeFalmer.

Kolb, D. A. (1984). Experiential learning. Englewood Cliffs, NJ: Prentice-Hall.

Lave, J. (1988). Cognition in practice. Cambridge: Cambridge University Press.

Lave, J. (1996). The practice of learning. In S. Chaiklin \& J. Lave (Eds.), Understanding practice: Perspectives on activity and context (pp. 3-34). Cambridge, UK: Cambridge University Press.

Lave, J., \& Wenger, E. (1991). Situated learning: Legitimate peripheral participation. Cambridge, NY: Cambridge University Press.

Loynes, C. (2002). The generative paradigm. Journal of Adventure Education and Outdoor Learning, 2(2), 113-125. 
Luckner, J. L., \& Nadler, R. S. (1997). Processing the experience: Strategies to enhance and generalize learning (2nd ed.). Dubuque, IA: Kendall Hunt.

Martin, B., Cashel, C., Wagstaff, M., \& Breunig, M. (2006). Outdoor leadership: Theory and practice. Champaign, IL: Human Kinetics.

Mehan, H. (1996). Beneath the skin and between the ears: A case study in the politics of representation. In S. Chaiklin \& J. Lave (Eds.), Understanding practice: Perspectives on activity and context (pp. 241-268). Cambridge, NY: Cambridge University Press.

Michelson, E. (1996). Usual suspects: Experience, reflection and the (en)gendering of knowledge. International Journal of Lifelong Education, 15(6), 438-454.

Michelson, E. (1999). Carnival, paranoia and experiential learning. Studies in the Education of Adults, 31(2), 140-154.

Panicucci, J. (2007). Cornerstones of adventure education. In D. Prouty, J. Panicucci \& R. Collinson (Eds.), Adventure education: Theory and applications (pp. 33-48). Champaign, IL: Human Kinetics.

Priest, S., \& Gass, M. A. (1997). Effective leadership in adventure programming. Champaign, IL: Human Kinetics.

Proudman, B. (1995). Experiential education as emotionally engaged learning. In K. Warren, M. Sakofs \& J. S. Hunt, Jr. (Eds.), The theory of experiential education (3rd ed., pp. 240-247). Dubuque, IA: Kendall/Hunt.

Prouty, D. (2007). Introduction to adventure education. In D. Prouty, J. Panicucci \& R. Collinson (Eds.), Adventure education: Theory and applications (pp. 3-17). Champaign, IL: Human Kinetics.

Quay, J. (2002). The importance of context to learning: Physical education and outdoor education seeing eye to eye. Paper presented at the Australian Council for Health Physical Education and Recreation, Adelaide, SA.

Quay, J. (2003). Experience and participation: Relating theories of learning. Journal of Experiential Education, 26(2), 105-116

Ringer, M. (1999). The facile-itation of facilitation? Searching for competencies in group work leadership. Scisco Conscientia, 2, 1-19.

Roberts, J. (2008). From experience to neo-experiential education: Variations on a theme. Journal of Experiential Education, 31(1), 19-35.

Rogoff, B. (2003). The cultural nature of human development. Oxford: Oxford University Press.

Ross, L., \& Nisbett, R. (1991). The person and the situation. New York: McGraw Hill.
Sawada, D. (1991). Deconstructing reflection. The Alberta Journal of Educational Research, XXXVII(4), 349-366.

Seaman, J. (2007). Taking things into account: Learning as kinaesthetically-mediated collaboration. Journal of Adventure Education and Outdoor Learning, 7(1), 3-20.

Seaman, J. (2008). Experience, reflect, critique: The end of the "learning cycles" era. Journal of Experiential Education, 31(1), 3-18.

Shoda, Y., \& Mischel, W. (2000). Reconciling contextualism with the core assumptions of personality psychology. European Journal of Personality, 14, 407-428.

Sugarman, D. A., Doherty, K. L., Garvey, D. E., \& Gass, M. A. (2000). Reflective learning: Theory and practice. Dubuque, IA: Kendall/Hunt.

Vince, R. (1998). Behind and beyond Kolb's learning cycle. Journal of Management Education, 22(3), 304-319.

Walsh, V., \& Golins, G. (1976). The exploration of the Outward Bound process. Denver, CO: Colorado Outward Bound School.

Wenger, E. (1998). Communities of practice: Learning, meaning and identity. Cambridge: Cambridge University Press.

Wilson, A. (1993). The promise of situated cognition. New Directions for Adult and Continuing Education, 57, 71-79.

Wurdinger, S. (1995). A critical interpretation of commonly held assumptions in adventure education. The Journal of Adventure Education and Outdoor Leadership, 12(2), 6-10.

Zink, R., \& Boyes, M. (2006). The nature and scope of outdoor education in New Zealand schools. Australian Journal of Outdoor Education, 10(1), 11-21.

\section{About the author}

Mike Brown, PhD is a senior lecturer in the Department of Sport and Leisure Studies at The University of Waikato. He has worked on outdoor education in the UK, Australia and New Zealand. Recent publications have drawn on research from the broader educational field and have suggested ways in which this might inform outdoor education theory/ practice. In addition to academic pursuits he is a keen sea kayaker and triathlon 'addict.' Email: michaelb@ waikato.ac.nz 
Reproduced with permission of the copyright owner. Further reproduction prohibited without permission. 